\title{
Surface-Based Fractional Transport Rates: Mobilization Thresholds and Partial Transport of a Sand-Gravel Sediment
}

\author{
Peter R. Wilcock and Brian W. McArdell
}

\author{
Department of Geography and Environmental Engineering, Johns Hopkins University, Baltimore, Maryland
}

\begin{abstract}
Twenty-eight coupled observations of flow, transport, and bed surface grain size distribution were made in a laboratory flume using a wide range of flows and a sediment with a very poorly sorted, bimodal grain size distribution. These observations permit the transport rates of individual size fractions to be scaled by the proportion of each size immediately available for transport on the bed surface. The key to our observations is the use of a sediment in which each size fraction has been painted a different color, which permits reliable, repeatable, and nondestructive measurement of the bed surface grain size distribution from photographs of the bed surface. At a given flow, the fractional transport rates may be divided into two parts: a finer-grained portion within which fractional transport rates are a function only of their proportion on the bed surface and total transport rate, and a coarser-grained portion for which fractional transport rates also depend on the proportion of individual grains within a fraction that remain essentially immobile throughout the experimental run. We define the latter condition as one of partial transport and observe that the grain size separating partial and fully mobilized transport consistently increases with flow strength. Complete mobilization of a size fraction occurs at roughly twice the shear stress necessary for incipient motion of that fraction. Zones of partial and full mobility are quite distinct when fractional transport rates are scaled by the bed surface grain size distribution, although a region of partial transport is evident when these data and other experimental and field observations are scaled by the bulk grain size distribution of the sediment bed. Critical shear stresses for the incipient motion of individual fractions in our experimental sediment vary over an order of magnitude, a result strongly in contrast to many earlier observations, but consistent with our observations of incipient motion in sediments with bimodal grain size distributions.
\end{abstract}

\section{INTRODUCTION}

It is well established that the transport of mixed-size sediments by running water leads to the development of a bed surface that has a grain size distribution different than that of the sediment bed. The transport observed at any instant is a function of the grain sizes immediately available for transport on the bed surface. Generally, however, the only known size distribution is that of some larger volume of the sediment bed. The transport is related to this bulk grain size distribution only through the surface sorting that the bed undergoes as it adjusts to the imposed flow and transport fields. Comparisons among transport observations at different sites, or at different times at the same location, require some accounting for these adjustments, which are often complex and poorly understood. The absence of directly correlated observations of transport and bed surface size distribution presents a fundamental obstacle to the unambiguous evaluation of the physical processes inherent in any set of transport observations and precludes the availability of a general and consistent set of transport data against which general theory may be tested.

A direct approach to this problem can be achieved by correlating individual observations of fractional transport rates with the size distribution of the bed surface from which the transport is entrained. The bed surface size distribution is considerably more difficult to measure accurately than the transport and has been the limiting factor preventing the development of a general and consistent set of surface-based

Copyright 1993 by the American Geophysical Union.

Paper number 92WR02748.

0043-1397/93/92WR-02748\$05.00 transport data. We present here many coupled observations of flow, transport, and bed surface size distribution from a series of flume runs at different flow strengths. The key to our observations is the use of an unusual sediment bed in which each size fraction has been painted a different color. This permits reliable, repeatable, and nondestructive measurement of the bed surface grain size distribution from photographs of the bed surface. Because our bed surface observations and direct scaling of transport with the bed surface texture are substantially different from previous work, we provide some emphasis in this paper on the methods used, our assessment of their accuracy and repeatability, and the degree to which our conclusions depend on the particular observations we make.

Because the measurements we can make with the painted sediment are unlikely to be widely replicated, we attempt in this paper to organize our results in a fashion that may be readily generalized. To do this, we find it useful to define two thresholds for bed load transport. One is the familiar critical shear stress $\tau_{c i}$ for incipient motion of fraction $i$. Operationally, such a threshold cannot be measured precisely and is replaced by the shear stress that produces a very small reference transport rate. The second threshold has not been previously defined. It lies above the initial-motion threshold and, taken together with $\tau_{c i}$, defines a region within which the transport rates for some (coarser) fractions are substantially smaller than the transport rates of other (smaller) fractions. We define this condition as partial transport and propose that the diminished transport rates occur because only a portion of the grains in partially mobilized fractions are entrained with any measurable frequency (as opposed to the competing hypothesis that all grains in these fractions 
move with a much smaller average frequency). For combinations of bed shear stress and grain size that fall above the upper threshold, the proportions of each fraction in transport and on the bed surface are comparable, and we term this region fully mobilized transport, suggesting that all of the grains in fully mobilized fractions are entrained regularly.

The importance of recognizing and defining a region of partial transport lies in the fact that the fractional transport rates in such a region will depend on the proportion of each fraction that is mobile. In the fully mobilized region, the total proportion of each fraction on the bed surface determines the fractional transport rates; in the partial transport region, the proportion of surface grains that are mobile must also be known. Because partial transport depends on the proportion of grains available for transport on the bed surface, the surface-based transport observations we make here allow a clear definition of the domain of partial and complete mobility for our experimental sediment.

The partial transport concept is inextricably linked to the operational configuration of the transport system. In the experiments reported on here, both sediment and water are recirculated until the transport reaches a steady state. In such a system, the upstream sediment input is determined entirely by the grains entrained within the flume. Any size fractions that are inherently less mobile will have a corresponding diminished presence in the sediment input. Partial transport results from differences in grain mobility; by maintaining a diminished input of less mobile sizes, a recirculating flume permits a partial transport condition to exist at steady state. In a later paper, we will present the results of experiments currently under way in which the same sediment mixture is fed at a constant rate into the upstream end of the flume. Under sediment feed conditions, sizes with a lower mobility become increasingly represented on the bed surface until their transport rate matches the feed rate at steady state [Parker and Klingeman, 1982; Parker and Sutherland, 1990; Wilcock and Southard, 1989]. In the feed case, the steady state bed surface size distribution is entirely determined by the flow and the upstream sediment input and is independent of the initial sediment bed. The proportion of each fraction on the bed surface depends directly on its proportion in transport: A condition of partial transport cannot be maintained under steady state sediment feed conditions (G. Parker and P. R. Wilcock, Sediment feed and recirculating flumes: A fundamental difference, submitted to Journal of Hydraulic Engineering, 1992). In a recirculating flume, the upstream sediment boundary condition is a dependent variable, and the steady state bed surface texture depends on both the inherent mobility of different sizes and the initial sediment bed. A condition in which some fractions on the bed surface are partially immobile can be maintained under steady state recirculating transport.

\section{Motivation For Surface-Based TRANSPORT OBSERVATIONS}

The inherent difference between sediment feed and sediment recirculating flumes provides a useful example that illustrates the importance of scaling fractional transport rates with the grain size distribution of the bed surface rather than the bulk sediment. Consider two parallel experiments, one in a sediment recirculating flume and the other in a sediment feed flume. Both experiments are designed to measure

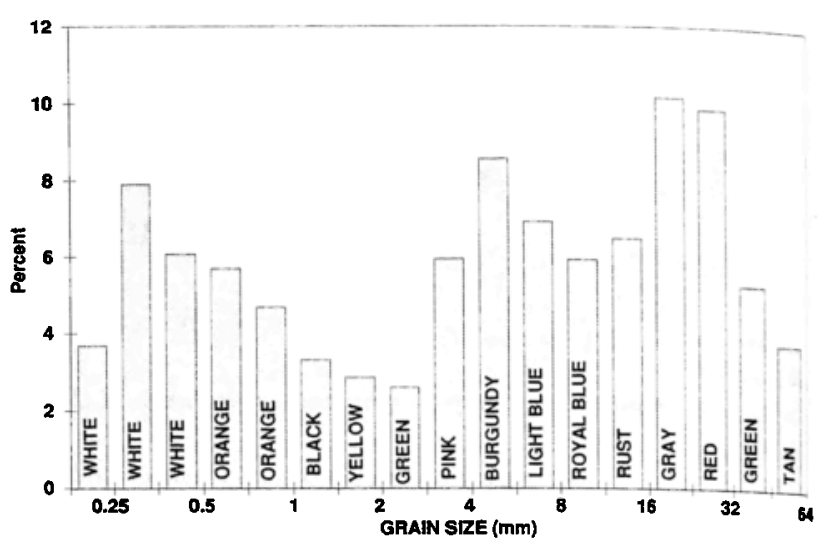

Fig. 1. Histogram of the grain size of the bulk "bed of many colors" (BOMC) mixture. The color of each $1 / 2 \phi$ size fraction is given within the histogram bar.

fractional transport rates as a function of flow strength. Each experiment uses the same sediment mixture and range of flows over which fractional transport rates are measured. In general, a different combination of bed surface texture and fractional transport rates can develop in each flume at a given flow. (We have observed this to be the case with the sediment discussed in this paper.) If, for a given flow, the fractional transport rates differ between the two flumes, but are scaled by the proportion of that fraction in the bulk mixture (which is the same in both cases), the results of the two experimental programs must be in conflict. To be consistently compared, the fractional transport rates must be scaled by the grain size distribution of the bed surface from which the transport is entrained. This example makes use of the different operational controls of laboratory flumes to directly illustrate the problems inherent in using a size distribution other than the bed surface to scale fractional transport rates. The problem is not unique to flumes, however, but occurs whenever the bed surface is sorted relative to the bulk sediment mixture, whether in field or flume.

A previous effort has been made to develop a surfacebased fractional transport model [Parker, 1990]. This work was based on the transport observations made by Milhous [1973] on Oak Creek, Oregon. In developing the model, Parker inverted an empirical fractional transport model to predict the bed surface size distribution from the transport. The work presented here is designed to provide direct observations of transport and bed surface size distribution for a range of flows.

\section{METHODS}

\section{Sediment}

The experimental sediment was prepared by sieving roughly $3200 \mathrm{~kg}$ of source sediments into 14 different size fractions to make $2000 \mathrm{~kg}$ of experimental sediment ranging in size from 0.21 to $64 \mathrm{~mm}$. Standard $1 / 2 \phi$ size fractions were used to define all fractions coarser than $1.0 \mathrm{~mm}$; grains in the 0.5-1.0 mm range were combined into one fraction, as were all grains less than $0.5 \mathrm{~mm}$. Before recombining the fractions, we painted all grains of each size fraction a different color. The size distribution and color scheme are given in Figure 1. Samples of each color were sieved to determine the 
TABLE 1. Mean of Hydraulic and Transport Observations for Experimental Runs and Summary of Transport Sampling Frequency and Duration

\begin{tabular}{|c|c|c|c|c|c|c|c|c|c|}
\hline \multirow[b]{2}{*}{ Run } & \multirow[b]{2}{*}{$\begin{array}{c}\text { Flow } \\
\text { Depth, } \\
\text { cm }\end{array}$} & \multirow{2}{*}{$\begin{array}{c}\text { Water } \\
\text { Surface } \\
\text { Slope, } \\
\%\end{array}$} & \multirow{2}{*}{$\begin{array}{c}\text { Mean } \\
\text { Flow } \\
\text { Velocity, } \\
\text { cm s }^{-1}\end{array}$} & \multirow[b]{2}{*}{$\begin{array}{c}\text { Surface } \\
\text { Velocity, } \\
\text { cm s s}^{-1}\end{array}$} & \multirow[b]{2}{*}{$\begin{array}{l}\text { Bed Shear } \\
\text { Stress, Pa }\end{array}$} & \multirow[b]{2}{*}{$\begin{array}{c}\text { Total } \\
\text { Transport } \\
\text { Rate, } \\
\mathrm{g} \mathrm{m}^{-1} \mathbf{s}^{-1}\end{array}$} & \multirow{2}{*}{$\begin{array}{c}\text { No. of } \\
\text { Coupled } \\
\text { Flow, } \\
\text { Transport, } \\
\text { and Bed } \\
\text { Surface } \\
\text { Observations }\end{array}$} & \multicolumn{2}{|c|}{$\begin{array}{c}\text { Total Duration of } \\
\text { Transport Sampling, } \\
\text { min }\end{array}$} \\
\hline & & & & & & & & $\begin{array}{c}\text { Fine } \\
\text { Fractions } \\
(\leqslant 16 \mathrm{~mm})\end{array}$ & $\begin{array}{c}\text { Coarse } \\
\text { Fractions } \\
(\geq 16 \mathrm{~mm})\end{array}$ \\
\hline BOMC $14 \mathrm{C}$ & 11.1 & 0.059 & 26 & 36 & 0.42 & 0.0023 & 1 & 180 & $\ldots$ \\
\hline BOMC 7a & 11.0 & 0.088 & 31 & $\cdots$ & 0.59 & 0.033 & 1 & 40 & $\cdots$ \\
\hline BOMC $14 \mathrm{~b}$ & 10.9 & 0.091 & 33 & 45 & 0.69 & 0.039 & 1 & 45 & $\cdots$ \\
\hline BOMC $7 \mathrm{~b}$ & 11.1 & 0.111 & 36 & $\cdots$ & 0.80 & 0.095 & 2 & 60 & $\cdots$ \\
\hline BOMC 7c & 10.5 & 0.174 & 46 & 58 & 1.33 & 0.43 & 2 & 75 & $\cdots$ \\
\hline BOMC 1 & 12.0 & 0.180 & 56 & 70 & 1.73 & 5.8 & 4 & 8 & $\cdots$ \\
\hline BOMC 2 & 11.2 & 0.315 & 60 & 80 & 2.47 & 7.1 & 6 & 103 & $\cdots$ \\
\hline BOMC 6 & 9.6 & 0.685 & 82 & 108 & 4.67 & 125 & 2 & 3 & 135 \\
\hline BOMC 4 & 9.4 & 0.765 & 87 & 111 & 5.02 & 157 & 5 & 189 & 424 \\
\hline BOMC 5 & 8.8 & 1.62 & 108 & 149 & 7.27 & 572 & 4 & 108 & 174 \\
\hline
\end{tabular}

efficiency of the sieving and painting. The mean percent of each color falling within the prescribed size fraction was $95 \%$, with all fractions having at least $91 \%$ of each color falling within the prescribed size fraction. The size distribution of this sediment matches one currently being used in a larger-scale flume experiment on downstream size sorting at the Saint Anthony Falls Hydraulic Laboratory. The size distribution was selected to be broadly representative of common size distributions in natural gravel bed streams and to provide a sufficiently wide range of grain sizes that downstream sorting could be observed on a laboratory scale [Paola et al., 1992].

The mean specific gravity of all size fractions was 2.61 ; the maximum deviation from this mean was $5 \%$. The $4.0-8.0 \mathrm{~mm}$ size fractions contain some chalky limestone clasts, which lowers the mean density for these fractions to 2.49 . The clasts between 8.0 and $32 \mathrm{~mm}$ contain a larger proportion of mafic minerals and have a mean specific gravity in the range 2.69-2.73.

Although an extraordinary effort was involved in producing this experimental sediment, unique measurement opportunities were made possible by the effort. Of the most significance to this paper is that we can measure the grain size distribution of the bed surface using point counts on photographs of the bed, which provides a reliable and statistically tractable estimate of the bed surface grain size distribution. Because each $1 / 2 \phi$ fraction is a different color, grain size can be positively identified from photographs, thereby avoiding the bias related to partial grain burial and grain orientation that has hampered previous attempts to use photographs to determine bed grain size distribution [ $A d-$ ams, 1979; Church et al., 1987]. Photographic sampling is also nondestructive, so we could sample the bed many times over the course of a run and measure progressive changes in the bed surface texture.

\section{Transport and Hydraulic Measurements}

We discuss here 10 experimental runs covering a range in shear stress from 0.42 to $7.3 \mathrm{~Pa}$ and a range in transport rate from 0.002 to $570 \mathrm{~g} \mathrm{~m}^{-1} \mathrm{~s}^{-1}$. We report on 28 coupled observations of flow, bed surface grain size distribution, and fractional transport rate. The basic hydraulic and transport observations are given in Table 1 . These values are means for all segments of a particular run. Also given in Table 1 are the number of bed surface observations and the duration of transport sampling in each run.

The experiments were conducted in a tilting laboratory flume with clear sidewalls. The channel is $60 \mathrm{~cm}$ wide with a working length of $790 \mathrm{~cm}$. A $120-\mathrm{cm}$ artificially roughened bed was installed upstream of the working section to develop the boundary layer before the flow encounters the loose sediment bed. Downstream of the working section is a 120-cm-long, full-width sediment trap (Figure 2). Water and sediment were recirculated separately. Most of the water passed with no overfall over the sediment trap into a tailbox and then through two centrifugal pumps and a $20-\mathrm{cm}$ pipe to the upstream end of the flume. A small portion of the water discharge and most of the sediment finer than $16 \mathrm{~mm}$ passed through the sediment trap and were recirculated with an air-driven diaphragm pump through a 5 -cm plastic hose to the flume headbox. Coarser grains were caught on a 16-mm screen inside the sediment trap and manually returned to the flume headbox at periods ranging from 1 to $5 \mathrm{~min}$, depending on transport rate.

Sediment transport was sampled with three different meth-

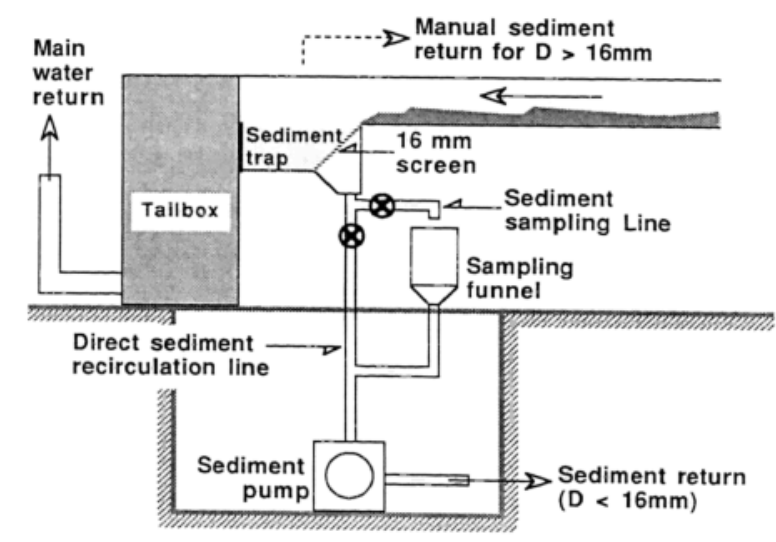

Fig. 2. Schematic illustration of the downstream end of the flume and the sediment sampling arrangements. Grains finer than 16 $\mathrm{mm}$ are sampled on a $0.21-\mathrm{mm}$ screen located in the sampling funnel and are recirculated via the sediment pump. Grains coarser than 16 $\mathrm{mm}$ are caught on a screen in the sediment trap and are recirculated manually. 
ods, a result of the separate recirculation paths of the fine and coarse grains and the competing requirements that we minimize disturbance of the transport during a run while also collecting enough samples to adequately measure the transport rates. Grains finer than $16 \mathrm{~mm}$ (which composed the entire sediment load for all but three runs) were sampled by diverting the sediment slurry from the trap to an open hose and directing the discharge onto a $0.18-\mathrm{mm}$ sieve placed inside a 100-L sampling funnel (Figure 2). All of the sediment was retained on the sieve, while the water was returned to the sediment recirculation system through a hose at the base of the funnel. This system allows the transport to be sampled over a wide range of periods, depending on the transport rate. In the experiments reported here, the sampling varied from catching all of the transport over 60 -min periods at the lowest transport rate of $0.0023 \mathrm{~g} \mathrm{~m}^{-1} \mathrm{~s}^{-1}$ to sampling eight out of every 60 seconds at the highest transport rate of $570 \mathrm{~g}$ $\mathrm{m}^{-1} \mathrm{~s}^{-1}$.

Because the total transport rate varies over a much broader range than the transport size distribution, the sampling period necessary to obtain a reliable estimate of the total transport rate is much longer than that needed to determine the transport size distribution. The total duration of sampling for each run is given in Table 1. During most of the sample period, only the total volume of transported sediment was measured, and the sample was then returned to the recirculation line through the sampling funnel within a period of $30 \mathrm{~s}$. This procedure permits measurement of the total transport rate with negligible disruption of the ongoing transport equilibrium. To determine the grain size of the transport and the conversion from volumetric to mass transport rate, samples collected immediately before the end of a run segment were saved, dried, and sieved. These samples were returned to the flume before the run continued. Fractional transport rates are calculated as $q_{b i}=\left(p_{i}\right) q_{b}$, where $p_{i}$ is the proportion of each fraction in transport and $q_{b}$ is the total transport rate.

The coarser sediment caught on the screen in the sediment trap was sampled by counting the numbers of grains of each color. Typically, the number of the two or three coarsest fractions caught on the screen could be counted and recorded during the cycle time set for manually recirculating the coarse sediment. An important advantage of this manual recycling effort is that we could monitor the rare motion of the coarsest grains throughout the run, providing a longer time series and more reliable estimate of their transport rate (Table 1). Samples of the coarse-grained transport were saved whenever the finer sediment sizes were sampled and saved. This samples were weighed and sieved to give a number-to-mass conversion for the gravel counts.

At the highest flow strengths, a portion of the finest fractions (predominantly sizes smaller than $1.0 \mathrm{~mm}$ ) would overpass the sediment trap and enter the flume tailbox. Although steps were taken to ensure that sediment in the tailbox was immediately recirculated by the main water pumps, this portion of the transport was unsampled. As discussed later in the paper, the undersampled transport rates of these finer fractions are evident at high flows. Only a limited amount of transport sampling was conducted for runs BOMC 1 and BOMC 6. The purpose of run BOMC 6 was to supplement our observations of the bed forms that develop with this sediment. Two other runs (BOMC 2 and BOMC 4) were conducted at flows producing transport rates very close to those of BOMC 1 and BOMC 6. The fractional transport rates for runs BOMC 1 and BOMC 6 are consistent with, but noisier than, those for runs BOMC 2 and BOMC 4 . and the results from the latter runs are used more extensively in this paper.

The elevation of the water and bed surfaces during a run were measured with acoustic transducers. Discharge was measured with a Venturi meter on the water return pipe. Discharge in the sediment recirculation line was nearly constant and always a small fraction of the main water discharge. Mean flow velocity was determined from the discharge, the mean flow depth, and flume width. Surface velocity was measured by timing the travel of surface tracers over a $5 \mathrm{~m}$ distance. Plastic bottle caps with a thickness of $1.5 \mathrm{~cm}$ and a diameter of $3 \mathrm{~cm}$ were used as tracers because they were found to float fully submerged with the upper side just at the water surface. The mean of the five fastest times out of 10 observations was used to determine the surface velocity for a particular run segment. Tracer tracks within 10 $\mathrm{cm}$ of the wall were discarded.

The bed shear stress was estimated using the dragpartition model of Einstein [1950], in which a flow hydraulic radius $R^{\prime}$ corresponding to the skin friction is computed iteratively from a Keulegan-type profile:

$$
\frac{U}{\left(g R^{\prime} S\right)^{1 / 2}}=\frac{1}{\kappa} \ln \left(\frac{R^{\prime}}{2.718 z_{0}}\right)
$$

where $U$ is mean channel velocity, $g$ is the acceleration of gravity, $S$ is the water slope, $\kappa$ is von Karman's constant, taken here to be 0.4 , and $z_{0}$ is a roughness length characteristic of the sediment bed. The quantity $\left(g R^{\prime} S\right)^{1 / 2}$ is the skin friction component of the bed shear velocity $u_{*}=\left(\tau_{0} / p\right)^{1 / 2}$. The bed roughness was calculated from the mean bed surface grain size distribution for each run as $z_{0}=D_{65} / 30$, where $D_{65}$ is the grain size for which $65 \%$ of the distribution is finer. Values of bed shear stress determined using (1) and the surface $D_{65}$ were $10-30 \%$ smaller than the total bed shear stress after the latter was corrected for wall effects [Vanoni and Brooks, 1957; Houjou et al., 1990]. Although the bed forms observed in this sediment were long and low, slip faces were observed in runs with bed form thicknesses sufficient to bury the largest grains on the bed surface. Equation (1) and the bed surface $D_{65}$ provide a skin friction estimate that shows a consistent variation with total bed shear stress, transport, and bed configuration from run to run. It also provides a basis of comparison with other mixed-size sediment transport observations [e.g., Wilcock and Southard, 1988; Wilcock, 1992, 1993].

\section{Bed Surface Grain Size Distribution}

The grain size distribution of the bed surface was measured by projecting photographs of the bed onto a grid and tallying the grain color (hence, size) falling on the grid intersections. Each photograph covered a bed section with dimensions of $20 \mathrm{~cm}$ in the cross-stream direction and $28 \mathrm{~cm}$ in the downstream direction. Individual grains were identifiable for all fractions coarser than $0.5 \mathrm{~mm}$. Grains smaller than $0.5 \mathrm{~mm}$ were all in the white size class. Two adjacent photographs provided continuous cross-stream coverage of $40 \mathrm{~cm}$. The remaining $10 \mathrm{~cm}$ on each side of the flume was not photographed. For this paper, point counts were made 


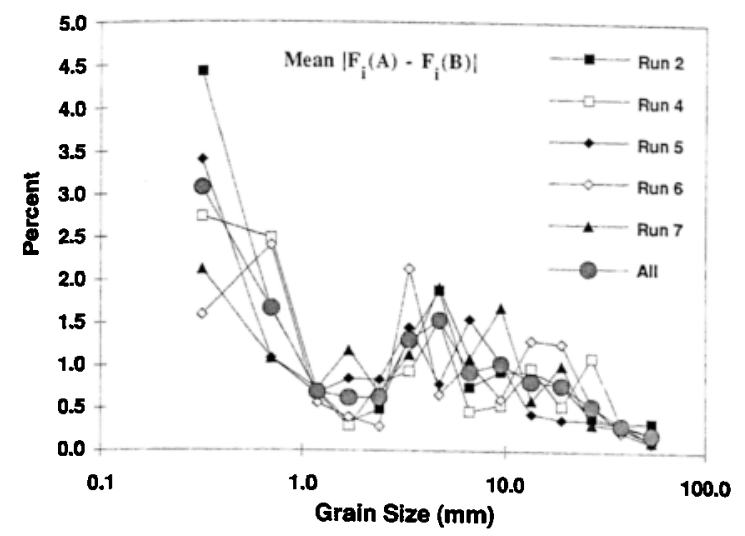

Fig. 3. The mean difference in the proportion of each grain size on the bed surface $\left(F_{i}\right)$ in replicate point counts of identical beds. Each point represents the average between-replicate difference in $F_{i}$ for each grain size and each run. The mean was calculated using the absolute value of the difference so that negative and positive differences would not cancel. Replicate counts were conducted on offset grids so that the same individual grains were generally not counted. Also shown is the mean between-replicate difference for each fraction, averaged over all 22 replicate point counts. The difference tracks the proportion in each grain size closely, suggesting that the variance in the estimate of $F_{i}$ is proportional to $F_{i}$.

on 14 contiguous photographs covering a $40 \times 196 \mathrm{~cm}$ bed area. Seventy points were counted on each photograph, providing a grain size sample of 980 points. Such a large number of points was used in order to estimate the proportion $F_{i}$ of each size fraction on the bed surface. The sample of 980 points includes at least 25 points for each size fraction in the bulk mix. The points were counted on two offset 4-cm-square grids. The cross-stream and downstream separation between grid points was $4 \mathrm{~cm}$, and the diagonal separation between grid points was $2.8 \mathrm{~cm}$. This spacing is smaller than the largest size on the bed, but the frequency of finding a single grain beneath more than one grid point was typically less than $1 \%$. These occurrences of repeat counts were almost always for grains that were immobile over the course of the run.

\section{Accuracy and Consistency of Bed Surface Point Counts}

The grid-by-number method used here to determine the bed surface grain size distribution has been shown to be equivalent to the volume-by-weight method commonly used in bulk sampling and sieve analyses [Kellerhals and Bray, 1971; Church et al., 1987]. It is not possible to precisely confirm this equivalence for our sediment because we know of no independent way to measure the true bed surface grain size distribution. We can, however, establish the consistency of our point counts by using replicate point counts and by comparing the mean surface size distributions of three manually prepared beds to the bulk size distribution. To evaluate the repeatability of the bed surface measurements, we conducted replicate counts of 980 grains for 22 of the 28 bed surface samples. The average of the absolute value of between-replicate differences (termed $A$ and $B$ counts) is plotted for each grain size and run in Figure 3. The differences tend to fall within $2 \%$, except for the two fractions smaller than $1 \mathrm{~mm}$, both of which have much larger proportions in the bulk mix. The between-replicate differences follow the bulk mix proportions closely, suggesting that the variance in our $F_{i}$ observations is proportional to $F_{i}$. When scaled by the mean of each replicate pair, the betweenreplicate differences for most sizes are smaller than $25 \%$. One exception is the $2.38-\mathrm{mm}$ fraction, which has scaled between-replicate differences as large as $40 \%$. This fraction has a dark green color that may have been occasionally mistaken for other dark colors. It is also the fraction with the smallest proportion (2.6\%) in the bulk mix.

We also compared the bulk grain size distribution to the mean surface size distribution of three beds that had been thoroughly mixed, screeded, slowly wetted, and drained (Figure 4). Although these screeded bed surfaces are not necessarily equivalent to either the bulk sediment mix or each other, the comparison does provide an absolute reference that could reveal sampling bias. The ratios of bed surface to bulk proportions $F_{i} / f_{i}$ in Figure 4 show a systematic decrease with grain size, which we attribute to selective sorting during the bed preparation process. If one assumes, in the absence of an obvious competing mechanism, that this trend is monotonic in grain size, the scatter about a mean trend suggests that orange, yellow, and pink grains may be overcounted, and that white, black, green, and burgundy grains are undercounted. With the exception of the white grains, this is a trend of overcounting brighter colors and undercounting darker colors. The white grains could be undercounted because they are unpainted and some are nearly clear, so that underlying grains may show through. This possible color-related bias is of the order of $10-30 \%$, which is comparable to the error we observe in our replicate counts.

Based on both the replicate point counts and the comparison between bulk and screeded beds, we suggest that a reasonable and conservative estimate of the error in measuring $F_{i}$ is $\pm 30 \%$ (e.g., for an observed $F_{i}=0.1$, the true value is likely to fall within 0.07 and 0.13 ). The actual error in most cases should be considerably smaller. The possible error in the $F_{i}$ values is reduced by using the mean of both replicates in the 22 cases for which replicate counts are available.

\section{Experimental Procedure}

Before each run, the bed was thoroughly mixed by hand and screeded flat in order to make the initial conditions for all runs as consistent as possible. Each run consisted of multiple segments; a suite of hydraulic and transport measurements were made during each segment, including water discharge, surface velocity, water and bed surface elevations, volumetric sampling of the finer-grained transport, and numerical sampling of the coarser-grained transport. Immediately before shutting down the flume, transport samples were taken and saved for size analysis. These samples can be correlated with the bed surface remaining at the end of the run segment. The flume was then drained and the bed surface photographed. The flume would be filled and another run segment commenced after the samples had been sieved and returned to the upstream end of the flume. After the last run segment was completed, the bed was completely rehomogenized in preparation for another run. Table 1 gives the number of run segments with coupled observations of flow, transport, and bed surface grain size distribution.

Almost all of the transport samples (including all those used below to determine the mean size distribution of the 


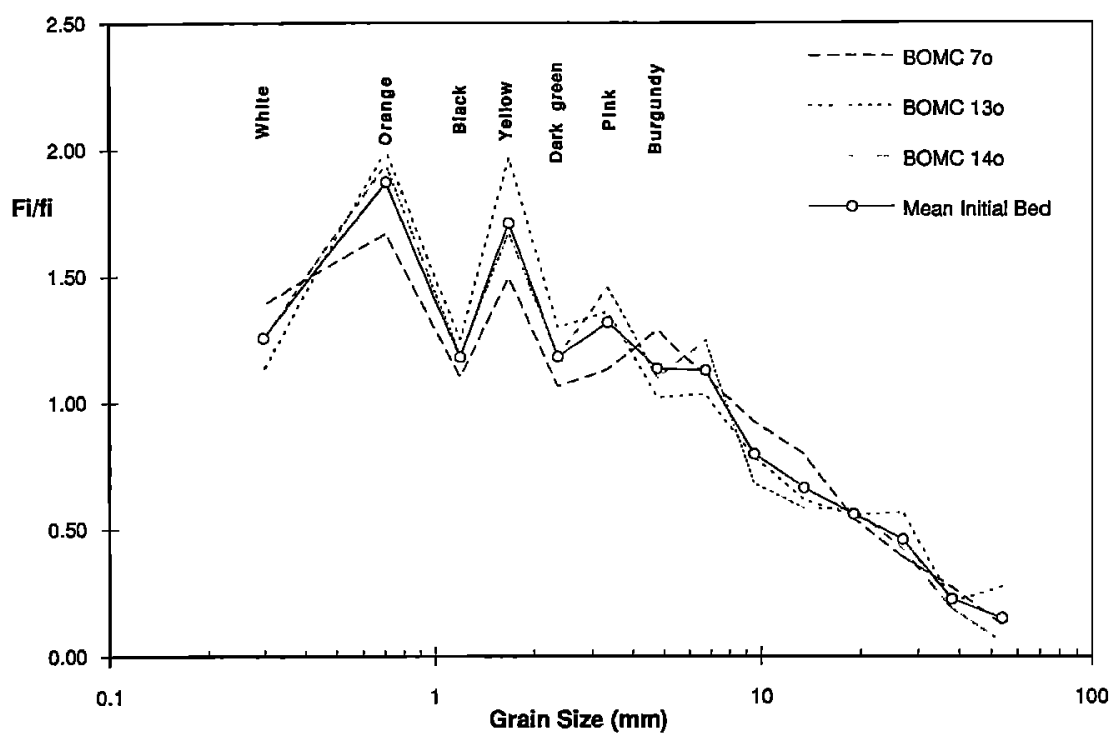

Fig. 4. The mean proportion of each size fraction on the bed surface $\left(F_{i}\right)$ for three initial sediment beds, scaled by the proportion of each fraction in the bulk mix $\left(f_{i}\right)$. The size distributions were determined from photographs of the bed after it was manually homogenized and screeded flat and the flume was slowly filled and then drained. The mean distribution is calculated using the arithmetic average of $F_{i}$ for the three individual beds.

transport) were collected for steady state conditions defined by fluctuations in transport rate and size distribution about a stable mean.

The procedure for runs BOMC 7 and BOMC 14 was slightly different. The purpose of these runs was to produce very low transport rates to provide a means of estimating incipient motion of the finer fractions. Because these runs involved very little modification of the bed (most grains on the bed did not move), runs $7 \mathrm{o}, 7 \mathrm{a}, 7 \mathrm{~b}$, and $7 \mathrm{c}$ and runs $14 \mathrm{o}$, $14 \mathrm{~b}$, and $14 \mathrm{c}$ were conducted with no remixing of the bed between runs, although the bed surface grain size distribution was measured following each transport sample. In essence, these runs were conducted in a sequence similar to the run segments in the other runs, except that the flow rate was changed between some of the segments.

\section{RESULTS}

\section{Complex Interactions Between Bed Surface Texture and Transport}

The bed surface and transport of this mixture show a complex, but consistent, variation with increasing flow strength. At the lowest flows (BOMC 7 series), the transport was composed almost entirely of sand sizes $(D<2.0 \mathrm{~mm})$. Most of the bed surface was covered by immobile coarser grains; portions of the sand fractions became organized into irregular and diffuse flow-parallel stripes. The bed surface grain size distributions of the BOMC 7 runs are shown in Figure 5a. As flow increases over this low-transport range, the bed coarsens relative to the initial bed. Most of the change in bed surface size distribution occurs in the fractions smaller than $1.0 \mathrm{~mm}$, which show a consistent decrease in proportion with flow strength. We assume that the relevant mechanism is a gradual filling of surface pore spaces by the fine sediments in motion. The initial screeding process does not completely fill the pore spaces on the bed surface; transport of the finer sizes in the absence of motion of the coarser sizes permits the surface pores to progressively fill with the sand. Also affecting the bed surface grain size distribution is the organization of the sand into weak, diffuse stripes, such that more of the sand in motion occupies a smaller proportion of the bed area. A similar decrease in the fine proportion on the bed surface with time has been previously observed at low transport rates with a more narrowly sorted sediment [Wilcock and Southard, 1989].

Although the bed coarsens with time in all of these low-transport runs, it is always finer than the bulk mixture size distribution. The latter observation is related to the overall proportion of sand in the bulk mixture. In sediments with a smaller proportion of sand and relatively open pore spaces, weak transport can produce the same coarsening over time we observe, but with the effect that most of the sand disappears into the pores and the bed surface becomes coarser than the bulk mix. In the BOMC sediment, gravelscale pores are entirely filled with sand, so the degree of vertical sorting possible in the presence of weak transport is relatively limited.

As flow strength increases, an increasing proportion of the gravel fractions are entrained into transport and long, low bed forms develop. The body of the bed form is primarily composed of sizes smaller than $1.0 \mathrm{~mm}$ and has a roughly flow-perpendicular crest and slip face. The bed forms have the shape and dimensions of a long, low dune, with dune length of the order of $50-100 \mathrm{~cm}$, and dune height of $1-2 \mathrm{~cm}$, which approximately corresponds to the maximum protrusion of the coarser grains in the sediment. The bed forms tend to be separated by a coarse region $20-100 \mathrm{~cm}$ in length. The bed forms reach a maximum height at flows correspond ing to our runs BOMC 4 and BOMC 6. At lower flows (BOMC 1 and BOMC 2), the bed configuration is transitional between these organized bed forms and the sandy streaks characteristic of very low transport rates. At higher flows (BOMC 5), the bed form spacing increases without gaining much height, producing a smaller height-to-spacing ratio. 

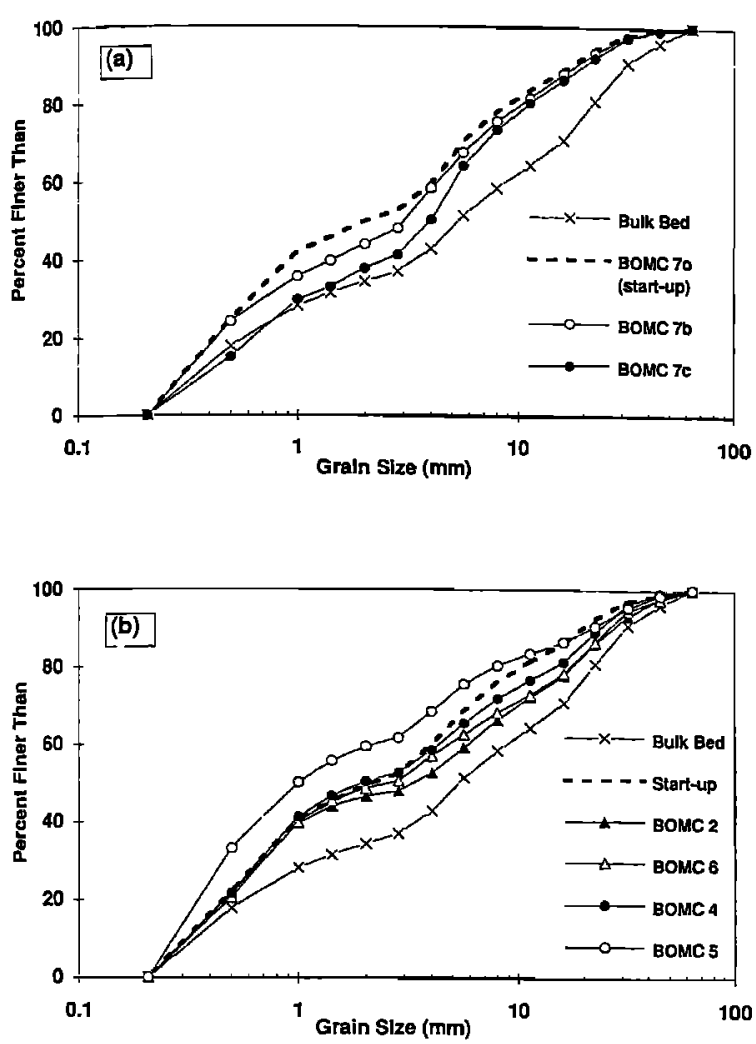

Fig. 5. Cumulative grain size distributions of the bed surface. All plots are the average of multiple measurements. (a) Runs at low transport rates: runs BOMC 7o (a start-up bed), BOMC 7b, and BOMC $7 \mathrm{c}$. The bed progressively coarsens with increasing bed shear stress. (b) Runs at higher transport rates: runs BOMC 2 , BOMC 6, BOMC 4, and BOMC 5. The bed becomes progressively finer with increasing bed shear stress. The start-up size distribution is the same as the mean initial bed distribution used in Figure 4.

These bed forms show a pattern of grain sorting that is made particularly clear by the coloring of the different grain sizes. Most of the bed form is composed of the finest (white) fraction. Coarser sand grains (orange and black) traverse the bed form in transient, spatially fluctuating, streaks and deposit at the downstream end of the bed form, creating a small, but distinctly colored, slip face of coarse sand. Gravel clasts move as single, isolated grains and rapidly traverse the body of the bed form without stopping. The coarsest grains in motion tend to traverse both the bed form and the intervening coarse zone without stopping. Most of the smaller gravel clasts tend to deposit in the intervening coarse zone within $50 \mathrm{~cm}$ of the dune slip face. The size selective trapping of these bed forms may play an important role in determining the mean transport rates of individual size fractions. We are presently investigating this process in more detail using video images of the grain-bed form interactions.

The spatial sorting in these bed forms is similar to the smooth and congested zones described by Iseya and Ikeda [1987] and the bed load sheets described by Whiting et al. [1988]. The size and shape of these bed forms are also similar to these grain-scale bed forms, as well as to dunes developed at low transport rates in a more narrowly sorted mixture [Wilcock and Southard, 1989]. We note that most of the grains traversing the bed form eventually stop moving within $50 \mathrm{~cm}$ of the sand crest, become buried by the advancing bed form, and are reentrained as the bed form moves downstream and the grains are reexposed to the flow. The exceptions to this dunelike grain path are the very coarsest grains in motion, which often overpass several bed forms, and a portion of the finest fraction, which moves over the bed in suspension.

The average bed surface grain size distributions of runs BOMC 2, 6, 4, and 5 are presented in Figure $5 b$ along with the bulk size distribution and the mean surface distribution of the three start-up beds shown in Figure 4. The bed surfaces of runs BOMC 2, 4, and 6 are coarser than the initial bed in the middle and larger percentiles, whereas the bed surface of run BOMC 5 is finer throughout the grain size distribution. In contrast to the runs at lower flows, the bed surface becomes consistently finer grained with increasing flow strength. Because an increase in $\tau$ causes the entrainment of an increasing proportion of gravel grains, we propose a sand-mining mechanism: As a larger proportion of the coarse grains are entrained, more fine sediment is exposed to the flow and made available for transport. In a closed transport system such as our recirculating flume, the net effect of this sand mining is an increase in the sand available for transport and a decrease in the mean grain size of the material actively in transport. At the highest run, BOMC 5, at least some of all sizes are in transport and a maximum number of coarse grains are entrained, thereby supplying the most sand to active transport of any of our runs and producing the finest bed surface.

It is worth noting that the adjustment between the transport and bed surface grain size distributions can be very different if the flume is operated by feeding the bulk sediment into the channel, rather than recirculating the transport, as done here. At low feed rates, the finer, more mobile sizes would be progressively winnowed from the bed, producing a bed surface that is significantly coarser than the bulk mix. In a feed system, the bed surface should be coarsest at very low transport rates and become progressively finer with increasing transport rate [Parker and Klingeman, 1982]. In the limit of high transport rates, for which all sizes are fully mobilized, the size distribution of both the transport and the bed surface should approach that of the bulk mix in either a sediment feed or recirculating system [Parker and Klingeman, 1982; Parker and Sutherland, 1990; Wilcock and Southard, 1989; Wilcock, 1992]. Differences between the two systems appear at lower transport rates, for which inherent differences in grain mobility can produce different equilibrium conditio is in response to the different boundary conditions for the two laboratory systems. These differences reinforce the importance of scaling the transport with the bed surface size distribution: Transport observations scaled by the population immediately available for transport should be independent of the system boundary conditions. In contrast, transport scaled by a bulk size distribution will depend on the system boundary conditions, because the relation between the bulk size distribution and the transport is mediated by surface sorting, which is, in turn, controlled by the boundary conditions.

\section{Choice of Spatial and Temporal Ranges to Average}

Spatially varying and downstream migrating patterns of bed surface texture require careful consideration of the appropriate spatial and temporal scales for surface-based 
transport observations. Different scales of space and time may be defined for the purposes of determining surfacebased transport rates. At the most detailed scale, individual samples of transport and the immediately adjacent bed surface texture provide a nearly instantaneous surface-based transport observation. Such observations are likely to come the closest to analytical transport models based on the near-bed flow structure and a force balance on individual grains. When spatial sorting of the bed surface occurs, however, both practical and theoretical problems make such sampling difficult. Often, areas of high transport migrate along the bed at a rate such that the bed changes significantly over the period needed to adequately sample the transport rate. A further problem with sampling at a nearly instantaneous time scale is that the dimensions of the bed surface area contributing to the measured transport are difficult to define. For example, if coarse grains travel greater distances than the fine grains, the different sizes within a sample will have been entrained from different areas of the bed. A final problem, which is partly a consequence of the first two problems, is the large degree of scatter typical of transport observations. It is often necessary to combine many samples in order to detect mean trends in the system.

Because of the inherent variability in both transport and bed surface texture, there is utility in combining individual transport/bed surface observations into a more stable average. If bed sorting occurs in clearly definable zones, or facies, samples for these zones may be combined into a time average of the instantaneous transport within each facies. The appeal of this approach is that it provides some control over the major source of variation in the transport field, while also permitting a more stable aggregate sampling approach. To describe the overall transport field, transport observations from each facies must be combined with estimates of the areal proportion and migration rate of each facies. This requires enough samples that the transport field over each facies is adequately described. The number of samples we have collected is not sufficient for this, in part because the size and shape of each facies were, although consistent in a qualitative sense, often quite small and variable for the purposes of direct measurement. The problem of grain provenance associated with individual samples also holds for aggregated facies samples. The finer grains moving over the bed forms are largely entrained from the bed form surface, whereas the coarse grains are entrained from a larger area and often move from one bed form to the next. It is difficult to define an appropriate area for a bed surface texture to scale these fractional transport rates.

The broadest scale for averaging surface-based transport observations is one that is sufficiently large (larger than one to several square meters for a typical sand and gravel bed) and long (several times the period of any observed transport fluctuations) to account for the local variability in the transport and bed surface texture. This approach is adopted here. Although combining samples at this scale does not permit a direct demonstration of instantaneous bed surface-transport interactions, both the bed and transport at this scale can be unambiguously defined, and reasonably stable values of mean bed surface and transport size distributions can be obtained. Table 1 gives the duration of transport sampling and the number of coupled observations of flow, transport, and bed surface grain size distribution. At lower runs (runs BOMC 1, 7, 14), the bed surface was relatively homoge- neous or varied over spatial scales much smaller than the dimensions of our photo grid, and all samples were used in determining the mean fractional transport rates and bed surface texture. At higher flows, these mean values were calculated for combinations of samples that approximated the average areal proportions of the different bed surface facies. All six samples were combined for BOMC 2, and both BOMC 6 samples were used. Only the last three samples were used for each of BOMC 4 and BOMC 5; the earlier samples were neglected because the bed and transport were visibly different from the stable steady state conditions developed later in the runs.

\section{Fractional Transport Rates}

The mean fractional transport rates from all 10 experimental runs are plotted as a function of grain size in Figure $6 a$. The fractional transport rates $q_{b i}$ are scaled by the proportion of each fraction on the bed surface $F_{i}$. Immediately evident in all runs is a systematic decrease in transport rate with grain size. A distinct break in slope is evident in most of the curves; the position of this break increases directly with the total transport rate. The transport rates of sizes finer than this break have a relatively small variation of $q_{b i} / F_{i}$ with grain size, approaching size independence in most cases. Because the transport is scaled by the proportion of each size present on the bed surface, a size independence in $q_{b i} / F_{i}$ indicates that the transport rates of the finer sizes are entirely determined by their proportion on the bed surface and the total transport rate of the entire mixture. This zone of size-invariant transport increases to include larger sizes with increasing total transport rates. The decrease in $q_{b i} / F_{i}$ evident for the finer fractions at the strongest flow (BOMC 5) is a result, at least in part, of undersampling the transport rate of those finer fractions that partly overpassed the sediment trap.

The fractional transport rates for each run span 2 or 3 orders of magnitude, and the overall range in transport for all runs is greater than 6 orders of magnitude, so that an error in determining $F_{i}$ of the order of $25-30 \%$, as suggested by the variability in our replicate point counts, would have a minor effect on the patterns evident in Figure $6 a$.

The decrease in transport rate with grain size present in Figure $6 a$ may be caused by several factors. Coarser grains may have a lower transport rate as a result of a lower mean velocity or a smaller frequency of entrainment. Visual observation of the transport suggests that differences in instantaneous grain velocity are not the likely explanation because coarse grains, when in motion, typically move rapidly and for great distances. The frequency of grain movement is more difficult to judge. Even a cursory inspection of the transport reveals that on a numerical basis, far fewer coarse grains are in motion than fine grains. It is far more difficult to judge differences in movement frequency on a mass basis, because grain mass increases as the cube of grain size.

A relevant observation we can readily make with the BOMC sediment is the proportion of grains that remain immobile over the duration of a run. Preliminary observations for grains coarser than $8 \mathrm{~mm}$ in run BOMC 2 (for which the coarsest size captured in the transport was in the 5.6-8.0 mm size class), show that roughly one third of the grains between 8 and $16 \mathrm{~mm}$ remained immobile over a 28-hour time period, whereas $92-96 \%$ of grains between 16 and 32 

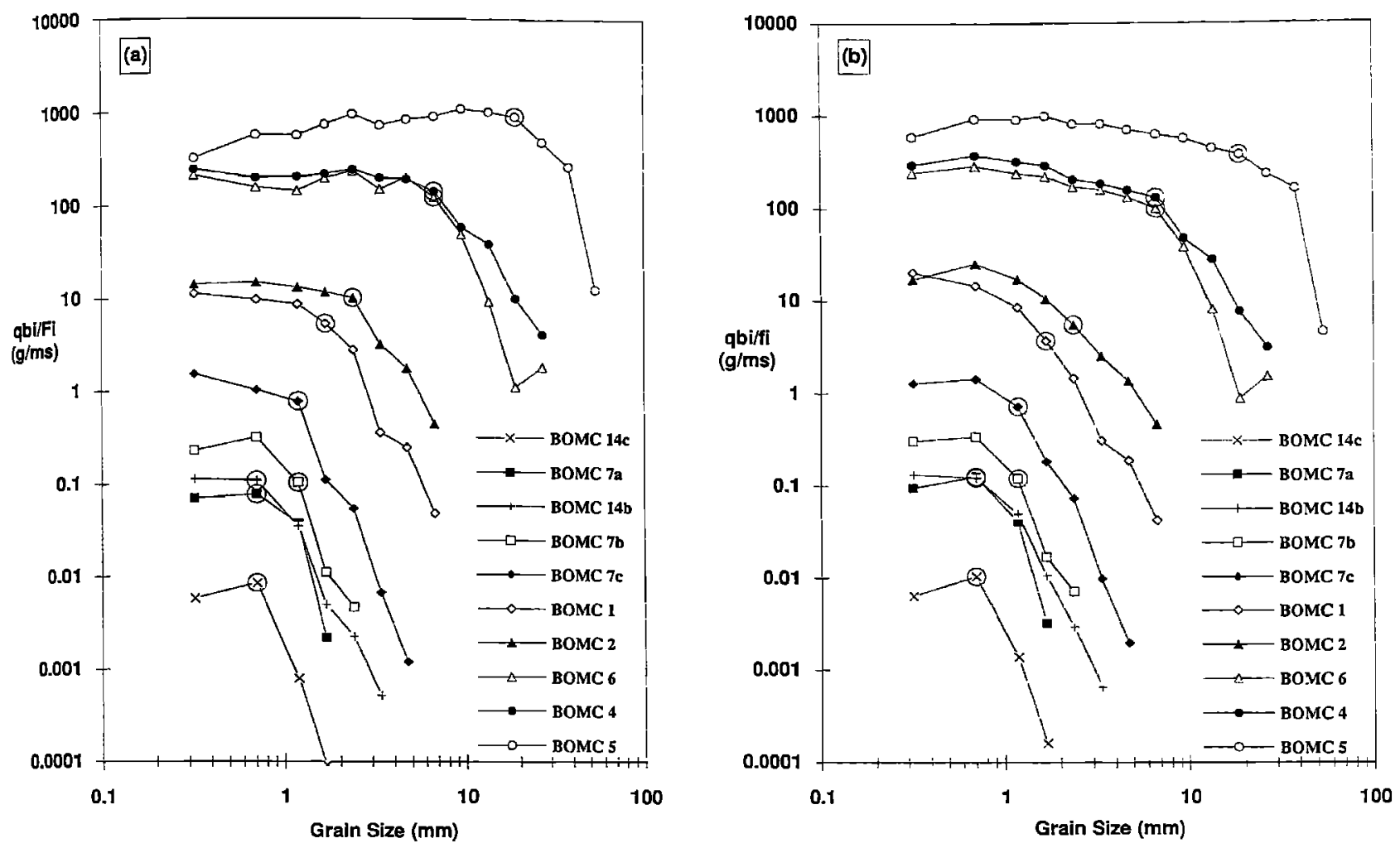

Fig. 6. Fractional transport rates $q_{b i}$ as a function of grain size. (a) Here $q_{b i}$ (in units of grams per meter per second) is scaled by the mean proportion of each fraction on the bed surface. Size independence in fractional transport rates plots as a line parallel to the size axis. The decrease in fractional transport rates at larger sizes is attributed to partial transport. Large, open circles represent the largest fully mobilized grain size in each run $\left(p_{i} / F_{i} \geq 1\right.$; see Figure 9 for the mobilization threshold of all sizes with a demonstrable threshold). (b) Here $q_{b i}$ is scaled by the proportion of each fraction in the bulk mix. The size independence of fractional transport rates at finer sizes and the size break between fully mobilized and partial transport are not as distinct in Figure $6 b$ as in Figure $6 a$.

$\mathrm{mm}$ remained immobile and all grains coarser than $32 \mathrm{~mm}$ remained immobile over the same time period. This suggests that beyond a certain threshold grain size (which is a function of the mean flow strength), the entrainment frequency decreases so rapidly with grain size that it may be useful to extend the concept to include the proportion of grains in a fraction that never move (over a specified period of time), as well as the frequency of entrainment of grains in that fraction that are occasionally transported. The entrainment frequency of the coarser, partially mobile fractions appears to be bimodal, with a few grains (typically more spherical and resting higher on the bed surface) entrained frequently and others (typically more bladed or disk shaped and located lower within the bed) entrained very rarely or not at all. We suggest that the two-part fractional transport patterns in Figure $6 a$ occur because all of the finer grains are entrained and transported at least part of the time, whereas only a portion of the coarser grains exposed on the bed surface are ever entrained. These are the modes of transport we term fully and partially mobilized.

The fundamental result that follows from this hypothesis is that the transport rates of the finer sizes may be determined entirely by their proportion on the bed surface and by the total transport rate of the entire mixture (to which the entrainment frequency is correlated), whereas the transport rates of the coarser sizes must be determined by their presence on the bed surface, the total transport rate, and the proportion of individval grains in those fractions that are never entrained.
The largest fully mobilized grain size is marked with a circle in Figure $6 a$. This is determined as the largest grain size for each run for which $p_{i} \geq F_{i}$. There is a consistent increase with transport rate in the largest fully mobilized grain size and this grain size falls near the break in slope for each run. This suggests that for each grain size, a threshold shear stress can be defined that separates a state of fully mobilized transport from one of partially mobilized transport. This threshold is analogous to, and larger than, the critical shear stress that defines the boundary between motion and no motion. This threshold is estimated for each grain size in the mixture and is discussed further below, after the threshold for initial motion is developed.

Fractional transport rates scaled by the bulk mixture size distribution $q_{b i} / f_{i}$ are given in Figure $6 b$. Overall, these fractional transport rates have a similar pattern to the surface-based rates, a result of the fact that the fractional transport rates vary (in a given run) over 2 orders of magnitude or more, whereas the proportions in the bed surface size distribution typically differ from the bulk size distribution by a factor of 3 or less (Figure 5). The difference between the two parts of Figure 6 is greatest in runs with the largest difference between the surface and bulk size distributions (e.g., runs BOMC 2, 6, 4, and 5). For these fractions, the important difference between Figures $6 a$ and $6 b$ is that the threshold grain size between partial and full mobility is more distinct in the surface-based data and the subhorizontal fractional transport pattern in the fully mobilized fractions is 

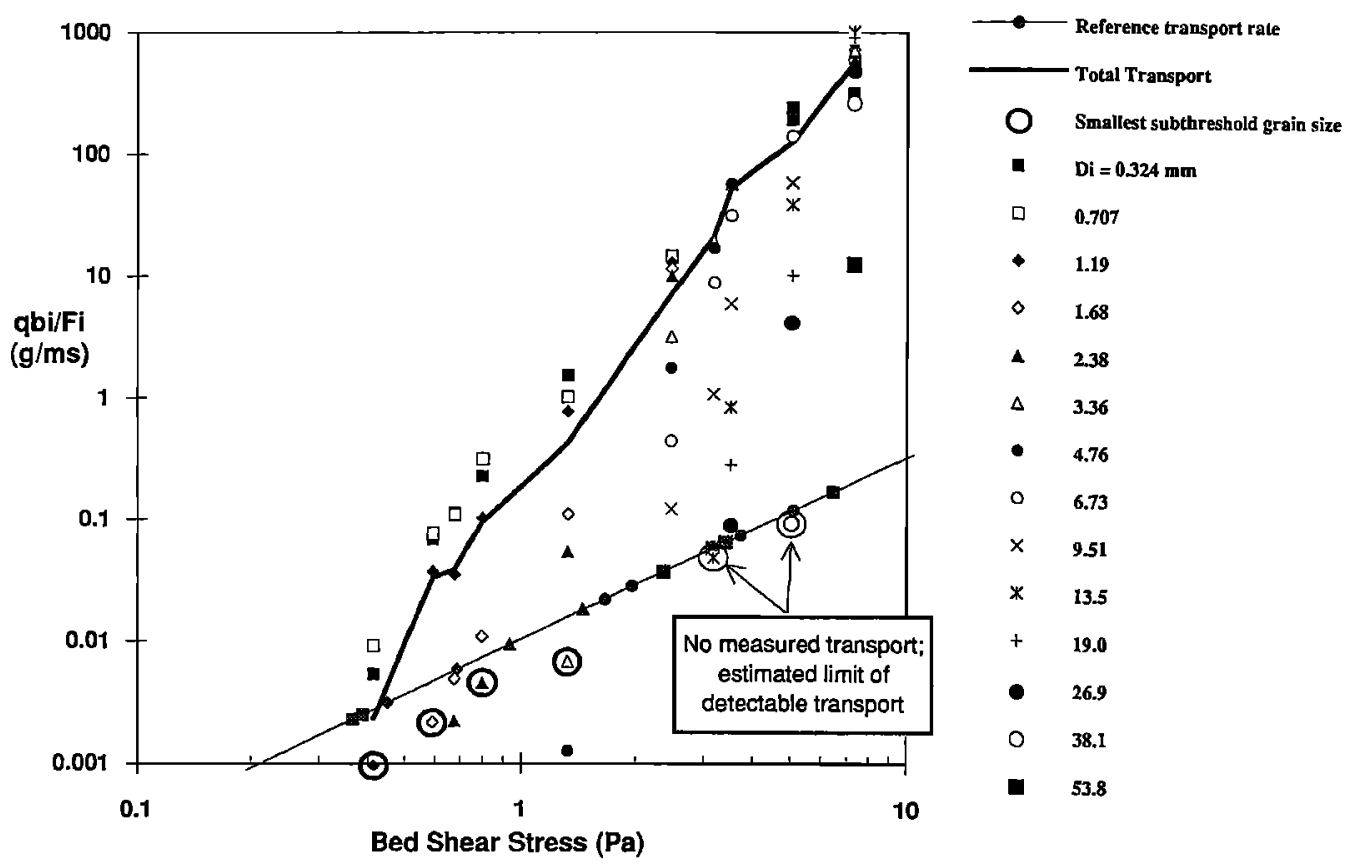

Fig. 7. Surface-based transport rates of each fraction as a function of $\tau_{0}$. Also shown is the reference transport relation $W_{i}^{*}=\mathbf{0 . 0 0 2}$. Estimates of $\tau_{r i}$ are shown as shaded symbols on the reference transport line. Different size fractions are entrained into measurable transport over nearly the full range of shear stresses used in these experiments. Large circles represent an alternative, lower bound estimate of $\tau_{r i}$ as the smallest fraction with transport rates below the reference level for particular runs. In cases for which there was no measured transport, the minimum detectable transport rate is estimated as the transport of one grain over the period of transport sampling.

more clearly evident in Figure 6a. Nonetheless, partial transport is clearly evident in both plots. Surface-based transport rates sharpen the definition of the two transport modes and provide a more consistent boundary between the two modes over the entire range of transport.

\section{THRESHOLDS}

\section{Threshold for Incipient Motion}

The threshold for initial motion of individual fractions, together with the threshold for fully mobilized transport, defines the domains of bed load transport of a mixed-size sediment. The initial-motion threshold, or critical shear stress for incipient motion of individual fractions $\tau_{c i}$, is estimated here as the shear stress $\tau_{r i}$ that produces a small, reference transport rate. This method has been used previously to estimate incipient motion conditions for a variety of mixed-size sediments [Parker et al., 1982b; Wilcock, 1992]. Among the advantages of this method are (1) it may be measured for all fractions in a mixture regardless of the distribution of $\tau_{c i}$ within the mixture, (2) it does not depend on sampling individual, rare, large grains in transport (such extreme values of the transport grain size distribution are difficult to sample accurately), and (3) because it is based on a transport rate, it is on a consistent basis with the threshold between partial transport and fully mobile transport. A more complete discussion of the reference transport method, along with results for other sediments, may be found in other papers [Wilcock, 1988, 1993; Wilcock and Southard, 1988].

The fractional transport rates, scaled by the surface grain size distribution, are presented as a function of bed shear stress in Figure 7. The data for runs BOMC 1 and BOMC 6 have been omitted for clarity; runs BOMC 2 and BOMC 4 have similar fractional transport rates and much greater sample periods (Table 1). Data from two runs with no measured bed surface texture have been added to the figure to provide additional coverage of gravel incipient motion. These runs are intermediate between runs BOMC 2 and 4 , with $\tau=3.2$ and $3.5 \mathrm{~Pa}$, respectively. The mean bed surface distribution of runs BOMC 2 and 4 were used to scale these fractional transport rates. Because the transport axis on Figure 7 spans 6 orders of magnitude, whereas the bed surface textures of runs BOMC 2 and 4 are similar (Figure $5 b$ ), the error involved in using an estimated bed surface texture for transport observations at the intermediate flow strengths is likely to be small. The fractional transport data are presented in a dimensional form in Figure 7 to directly illustrate the variation in fractional transport rates from size to size and to provide a better separation of the data. Also shown in Figure 7 is the reference transport rate used to determine $\tau_{r i}$. This is given by [Parker et al., 1982b]

$$
W_{r i}^{*}=\frac{q_{b i}(s-1) g}{F_{i} \rho_{s} u_{*}^{3}}=0.002
$$

where $s$ is the ratio $\rho_{s} / \rho, \rho_{s}$ sediment density, $\rho$ fluid density, $g$ the acceleration of gravity, and $u_{*}$ the bed shear velocity. In the units of Figure 7 , this relation is $q_{b i} / F_{i}=0.0104 \tau_{0}$, where the transport is given in grams per meter per second, the shear stress in pascals, and a sediment density of 2610 $\mathrm{kg} / \mathrm{m}^{3}$ is used.

It is evident from both Figures $6 a$ and 7 that the onset of measurable transport for different sizes occurs over nearly the full seventeen-fold range of $\tau_{0}$ used in these experiments. It is also evident that the relation between $q_{b i} / F_{i}$ and $\tau_{0}$ becomes progressively steeper with grain size, a phenome- 


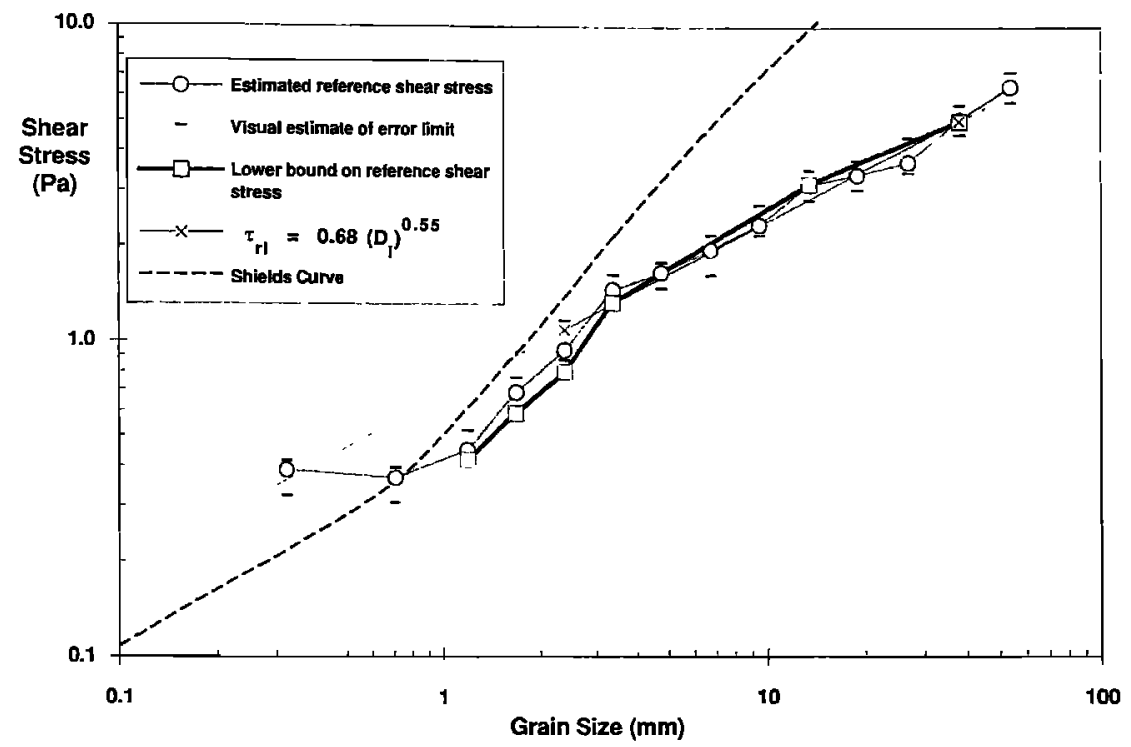

Fig. 8. Estimates of the reference shear stress for incipient transport of each fraction determined from the intersection of individual fractional transport curves with the reference transport line in Figure 7 . The values of $\tau_{r i}$ and the associated error were estimated by eye. The lower bound estimate of $\tau_{r i}$ is taken from the corresponding large circles in Figure 7. The Shields curve for incipient motion of unisize sediment is provided for comparison.

non previously noted for other sediments [e.g., Diplas, 1987; Kuhnle, 1992]. Both of these factors make it difficult to use a single $q_{b i} / F_{i}$ curve to estimate $\tau_{r i}$ for all grain sizes, as has been done previously [Wilcock, 1992]. Instead, the approach used here is to interpolate, where possible, between transport values falling close to, and on either side of, the reference transport line. Fractions between 1.0 and $5.7 \mathrm{~mm}$ have measured transport rates both above and below the reference line. All transport rates for the finest two fractions were above the reference level, although the smallest transport rate we measured $\left(0.0023 \mathrm{~g} \mathrm{~m}^{-1} \mathrm{~s}^{-1}\right)$ fell within an order of magnitude of the reference line. The value of $\tau_{r i}$ for these two fractions was determined by extrapolating a mean trend from the four lowest measured transport rates to the reference line.

Estimating $\tau_{r i}$ for the coarser fractions involved some additional consideration. Although we have measured fractional transport rates above the reference value for all fractions, we had no measured transport rates below the reference value for fractions coarser than $5.7 \mathrm{~mm}$. We can, however, make use of the absence of measured transport to estimate a maximum possible transport rate for a particular fraction and flow. This was done by estimating the smallest transport rate we could reliably detect and assuming the actual transport rate can be no larger. For the larger fractions, we take the minimum limit of detectable transport rate as one grain over the entire period of transport sampling. Two such points are shown on Figure 7. One is for $D=13.5$ $\mathrm{mm}\left(\tau_{0}=3.2 \mathrm{~Pa}\right.$; sample period, $\left.240 \mathrm{~min}\right)$; the other is for $D=38.1 \mathrm{~mm}$ ( $\tau_{0}=6.3 \mathrm{~Pa}$; sample period, $512 \mathrm{~min}$ ). In both cases, the detection limits are shown on Figure 7 for only the smallest grain size with no measured transport. Coarser fractions would have a larger limit of detection (because a single grain of the larger size has more mass), so we must assume that if the smallest grain size with unmeasured transport has subthreshold transport rates, all coarser sizes must also have subthreshold transport rates.
Because the form of the relations between fractional transport rate and $\tau_{0}$ varies with grain size, and because there is inevitable scatter in these data, estimates of $\tau_{r i}$ and the associated error were determined by eye. Our estimates of the intersection between the trend of fractional transport rates and the reference transport line are shown as shaded symbols (chosen to approximate the shape representing the associated fraction) on the reference transport line. The fact that the fitting involves some subjective judgment provided part of the motivation for showing the basic fractional transport rate data in Figure 7. We also made visual estimates of the minimum and maximum values $\tau_{r i}$ is likely to take for each fraction, which are shown along with the $\tau_{r i}$ estimates in Figure 8. Inspection of Figures 7 and 8 suggests that the true value of $\tau_{r i}$ for any particular fraction is likely to be within a factor of 1.4 of the estimated value and that the relative difference in $\tau_{r i}$ from fraction to fraction (and, therefore, the variation of $\tau_{r i}$ with grain size) can be estimated within a factor of 1.2. An approximate estimate of the error in our $\tau_{r i}$ estimates was made by fitting $\log$ straight lines to the transport data falling within 2 orders of magnitude of the reference value. The mean value of the ratio of these fitted estimates to those given in Figures 7 and 8 was close to one and the maximum difference was $10 \%$.

Because of the wide variation in $\tau_{r i}$, and because some fractions had measured transport rates for only one or two runs, a second estimate of the variation with grain size of $\tau_{r i}$ was made. If one assumes that $\tau_{r i}$ increases with grain size, as the general trend in the data suggests, the smallest grain size with subthreshold transport rates $\left(W_{i}^{*}<0.002\right)$ for a given run provides a lower bound estimate of the size just at threshold conditions for that flow. These lower limit estimates are shown in Figure 7 as circles around the appropriate data point. In four runs, the smallest subthreshold size has a measured value of $W_{i}^{*}$. In the two runs with the strongest flow, the smallest subthreshold size had no mea- 
sured transport and the limit of detectable transport is shown.

The two estimates of $\tau_{r i}$ are plotted as a function of grain size in Figure 8. The two trends are quite similar, providing some support that our estimates of $\tau_{r i}$ are reasonable. Also shown in the figure is a least squares trend $\tau_{r i}=$ $0.68\left(D_{i}\right)^{0.55}$ which is fitted to the fractions between 2.0 and $45 \mathrm{~mm}$. This curve also appears to fit values of $\tau_{r i}$ for $D_{i}=$ $0.32 \mathrm{~mm}$ and $D_{i}=53 \mathrm{~mm}$. The slope of this trend is strikingly different from many previous observations obtained with the same reference transport method and a variety of other sediments, in which exponents in the range 0.1 to -0.1 are typical. The result is consistent, however, with similar trends observed with strongly bimodal sediments [Wilcock, 1992]. Comparison of $\tau_{r i}$ values among these sediments suggests that the degree to which $\tau_{r i}$ varies with grain size depends on both the separation of the modes and the proportion of the overall size distribution contained in the modes [Wilcock, 1993].

The variation of $\tau_{r i}$ with grain size is sufficiently strong that possible errors in estimating $\tau_{r i}$ (of the order of a factor of 1.4 for absolute values and a factor of 1.2 for the relative change in $\tau_{r i}$ from fraction to fraction) are small compared to the overall variation of $\tau_{r i}$ in Figure 8 . The simple observation is that the fractional transport rates in Figure 7 cross the reference transport line over a wide range in $\tau_{0}$. A plot of fractional transport rates scaled by the bulk distribution $f_{i}$ is very similar to Figure 7 , and essentially identical values of $\tau_{r i}$ are obtained. This suggests that the trend in $\tau_{r i}$ is a basic property of the BOMC sediment, rather than a result particular to surface-based transport data.

\section{Full Mobilization}

The threshold between partial transport and fully mobilized transport was estimated for each grain size as the shear stress at which the ratio $p_{i} / F_{i}$ becomes greater than one. These estimates of the threshold of fully mobilized transport are shown in Figure 9, where they are plotted as a function of grain size. Also shown in Figure 9 are the $\tau_{r i}$ estimates, the Shields curve for unisize sediments, and the curve $u_{*}=$ $w$, where $w$ is the settling velocity, which provides an approximate estimate of the threshold for suspension transport.

The curves in Figure 9 define four transport regions. At $\tau$ $<\tau_{r i}$, fractional transport rates are negligibly small. Between $\tau_{r i}$ and the fully mobilized threshold, the scaled fractional transport rates are substantially smaller than those of smaller sizes, and at least some of the grains in the fraction are essentially immobile. For $\tau>\tau_{r i}$, the transport rates of all fractions are nearly equal, and we hypothesize that essentially all the grains in each fraction are regularly entrained. Finally, as $\tau$ approaches the curve $u_{*}=w$ for a particular size, a substantial proportion of the transport will occur as suspension.

The region of partial transport in Figure 9 is relatively constant in width. The fully mobilized threshold occurs over the range $1.8<\tau / \tau_{r i}<2.4$ with a mean value of $\tau=2.1 \tau_{r i}$. This suggests the simple approximation that a condition of partial transport exists over the range up to roughly twice the shear stress for incipient motion for each fraction. Although we have made direct observations of partial transport in only one particular sediment, it is possible that a similar partial

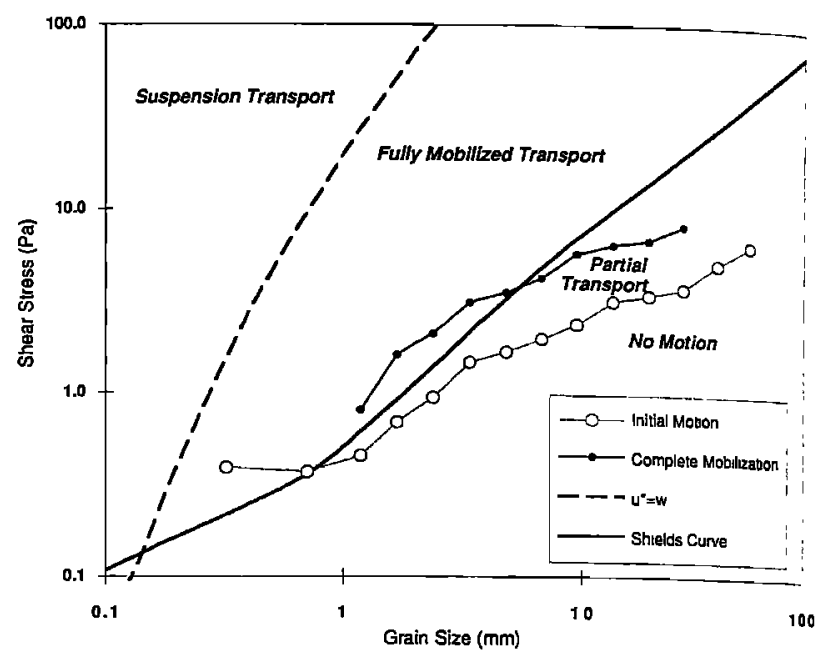

Fig. 9. Domains of bed load transport for the BOMC experimental sediment. The threshold between partially and fully mobilized transport is estimated as the value of $\tau_{0}$ that produces $p_{i}=F_{i}$ for each fraction. The initial-motion threshold is taken from Figure 8. The initial-motion and fully mobilized thresholds are separated by a factor of approximately 2 . The $u_{*}=w$ curve, where $w$ is the grain settling velocity, provides a rough estimate of the onset of substantial suspension transport.

transport region exists for all sediments, including those for which $\tau_{c i}$ is the same for all sizes. Partial transport would be evident in the grain size of the transport only when $\tau_{r i}$ varied with grain size.

For the purposes of comparison, the information in Figure 9 is replotted in Figure 10 in the standard dimensionless form of the Shields diagram for incipient motion. The shear stress is given as the Shields parameter $\tau^{*}=\tau_{0} /\left([s-1] \rho g D_{i}\right)$, where $s$ is the ratio $\rho_{s} / \rho$ and plotted as a function of the grain Reynolds number $u_{*} D_{i} / \nu$.

\section{Discussion}

Our experimental observations lead to particular conclusions that are either new or stand in contrast to some

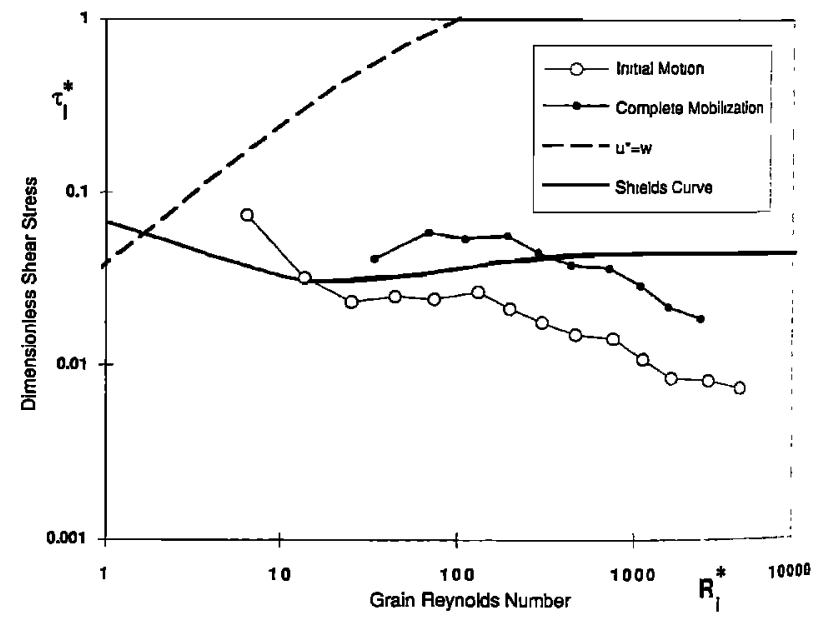

Fig. 10. Same as Figure 9, but plotted as a function of dimensionless shear stress $\left(\tau^{*}=\tau_{0} /(s-1) \rho g D_{i}\right)$ against the grain Reynolds number $R^{*}=\left(\tau_{0} / \rho\right)^{0.5} D_{i} / \nu$ to facilitate comparison with other work. 
previous concepts about mixed-size sediment transport. These results must be evaluated in terms of those aspects of our experiments that differ from previous ones. Of potential importance are the grain size distribution of the sediment we use, which is more poorly sorted and coarser than most flume sediments (although not natural fluvial sediments) and our particular methods of observing and scaling the fractional transport rates.

The methods we have used to determine the surface-based transport rates are simple and direct modifications of commonly used field methods. Our measurement of the bed surface texture is essentially the same as the point count method most commonly used to measure surface size distributions in the field [Wolman, 1954; Kellerhals and Bray, 1971; Church et al., 1987]. Our use of colored grains simply permits such counts to be made accurately from photographs, whereas in the field individual grains are commonly picked out of the bed and their size is directly measured. Nonetheless, the effort involved in making coupled measurements of the bed surface texture and transport is extreme and cannot reasonably find wide application. Some of the techniques we found necessary to collect these data, particularly coloring all the grains and draining the flume immediately after sampling the transport, cannot be directly replicated in the field. It is important, then, to distinguish the conclusions that depend on using surface-based fractional transport rates from those that are evident when the transport is scaled by the bulk size distribution.

\section{Partial Transport}

Our conclusions concerning the existence of partial transport are not dependent on the use of surface-based transport data because partial transport is evident in plots of both $q_{b i} / F_{i}$ and $q_{b i} / f_{i}$ (Figure 6). Our use of colored grains does uniquely support the partial transport hypothesis because we can easily track individual grains over a period of time to determine the proportion of each fraction that remains immobile.

There is fairly broad evidence that conditions of partial transport are common in the field. This is the mechanism invoked to explain bed armoring under conditions of zero sediment input, such as downstream of a reservoir. Partial transport under such conditions has been discussed by Proffitt and Sutherland [1983]. There are many descriptions of transport in rivers where only a portion of the sizes present in the bed sediment are in motion. Jackson and Beschta [1982] measured transport of only sand and fine gravel at lower discharges on Flynn Creek, Oregon, whereas transport at higher discharges involved all of the fractions present in the bed. Emmett [1976] observed that the size distribution of transport in the Snake and Clearwater rivers increased with discharge. Leopold [1992] recently summarized similar observations on several westem U.S. rivers.

Fine-grained transport over a coarser bed has previously been described as a "wash load" or "throughput" phenomenon [Milhous, 1973], wherein the transport is limited by the availability of sediment in the sizes the flow is capable of moving, rather than the competence of the flow. We agree with this only in part. The transport rate of the finer fractions during partial transport is clearly limited by availability, but the availability of the finer sizes is directly related to the mobility of all sizes in the sediment bed. The wash load

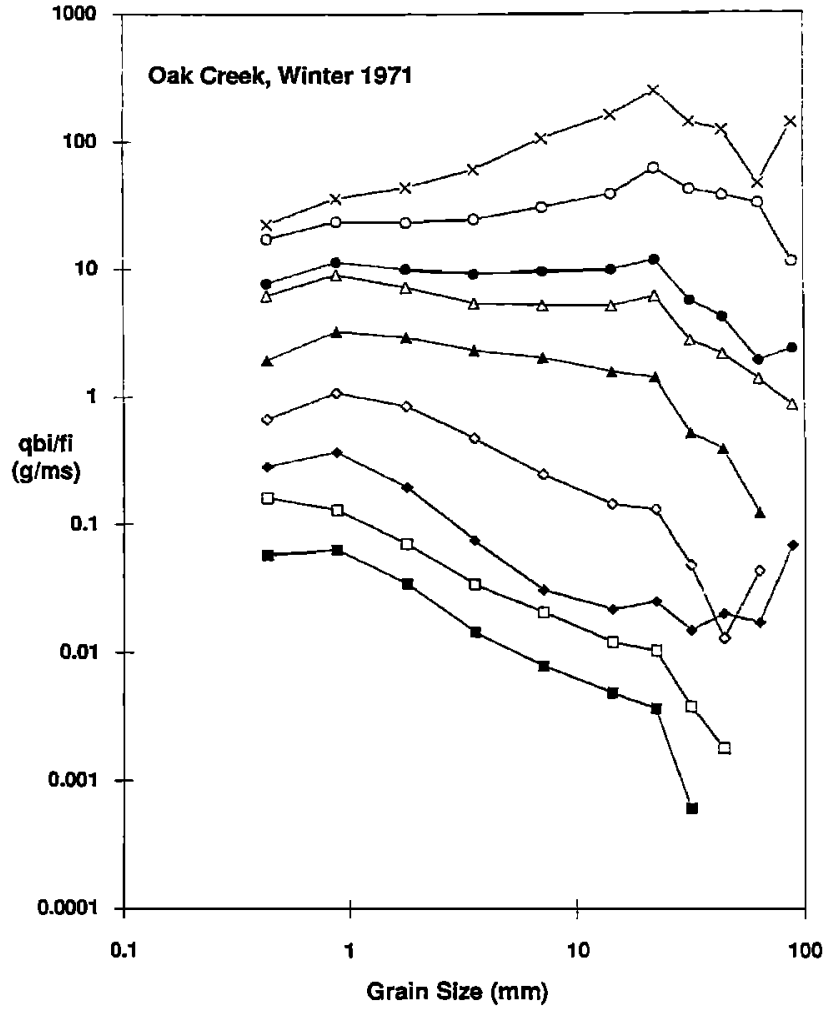

Fig. 11. Fractional transport rates $q_{b i}$ as a function of grain size for the Oak Creek data. Here $q_{b i}$ is scaled by the mean proportion of each fraction in the bulk sediment bed. The 34 winter 1971 samples for which water discharge exceeds $0.5 \mathrm{~m}^{3} / \mathrm{s}$ have been collapsed to nine samples by combining samples with transport rates falling within a factor of 1.5. Data from Milhous [1973]. The plot format is equivalent to that of Figure 6. A decrease in fractional transport rate with grain size is evident at the lower transport rates. The range in grain sizes over which this trend is observed decreases with transport rate.

concept makes the fine-grained transport an uncoupled and unpredictable component of a river's transport, whereas the partial transport we observe is an inherent part of the bed material transport and thus should be as predictable as the bed load at higher discharges. A further problem is that wash load is typically defined as sediment that is found in negligible proportions in the bed sediment. Clearly, this is not the case for our experiments, in which all transport must be derived from the sediment bed.

Partial transport is evident in two of the best available field data sets, those of Goodwin Creek, Mississippi [Kuhnle, 1992], and Oak Creek, Oregon [Milhous, 1973]. In both cases, a very large number of samples were taken and the entire transport load of the stream was captured, thereby minimizing the sampling problems created by the spatial and temporal variability of natural transport. Kuhnle [1992] presents a fractional transport plot equivalent to Figure $6 b$ which shows a consistent decrease in $q_{b i} / f_{i}$ with grain size and a consistent increase in the grain size separating what we term here the fully mobilized and partial transport zones. The winter 1971 Oak Creek fractional transport data are given in Figure 11 in the same format as Figure $6 b$. In order to incorporate lower transport rates, we have added 12 samples to the 22 samples previously analyzed by Parker et $a l$. $[1982 b]$. The additional samples include all those taken 
for a discharge greater than $0.5 \mathrm{~m}^{3} / \mathrm{s}\left(19 \mathrm{ft}^{3} / \mathrm{s}\right)$ and fall on the trend between total transport and shear stress for the 22 samples analyzed previously. The remaining 32 samples of the winter 1971 data set were taken for discharges less than $0.45 \mathrm{~m}^{3} / \mathrm{s}\left(16 \mathrm{ft}^{3} / \mathrm{s}\right)$, had very small transport rates, and show considerable scatter as a result of a wide variety of factors including the influence of organic debris and bed consolidation [Milhous, 1973]. We have collected the 34 samples into nine groups by combining samples that fall within a factor of 1.5 in transport rate.

The data in Figure 11 are scaled by the bulk grain size distribution of the bed sediment given by Parker et al. $[1982 b]$. A decrease in transport rate with grain size is clearly evident in these data at lower transport rates. Also, the grain size separating the equally mobile and partial transport zones increases with $\tau_{0}$. This increase is not continuous, as suggested by our surface-based transport results, but shows discrete values at $0.89,22.2$, and $63.5 \mathrm{~mm}$. A more continuous transition might be apparent if surfacebased transport data were available for Oak Creek (cf. Figures $6 a$ and $6 b$ ). The decrease in $q_{b i} / f_{i}$ for the smaller sizes at high transport rates is presumably due to undersampling of these sizes because they overpassed the sample slot [Milhous, 1973].

\section{Bed Load Thresholds}

We have defined two mixed-size bed load thresholds for our experimental sediment. A threshold between partial and fully mobilized transport has not, to our knowledge, been defined before. The incipient motion threshold shows considerably more size dependence in $\tau_{r i}$ than has been commonly observed using the same reference transport method.

Comparison of Figures $6 a$ and $6 b$ suggests that a threshold between fully and partially mobilized transport is more distinct when fractional transport rates are scaled by the bed surface grain size distribution. Also, the surface-based transport data are more nearly equally mobile for sizes below this threshold. Figure 9 suggests that partial transport exists over the range $1.0<\tau / \tau_{r i}<2.1$. Comparison of Figures $6 a$ and $6 b$ suggests that this partial transport range may be difficult to detect without surface-based transport data. Nonetheless, comparable results may be observed with other sediments. We observe both partial and fully mobilized transport in laboratory experiments with a mixed-size sediment with a lognormal grain size distribution, a mean size of $1.83 \mathrm{~mm}$, and a sorting of $1 \phi$ [Wilcock, 1992]. Although the range of $\tau_{r i}$ is only $20 \%$ for these data, the three coarsest fractions do not approach equal mobility until $\tau / \tau_{r i}>2.0$. A two-part mixture with equal modes at 0.66 and $5.2 \mathrm{~mm}$ develops fully mobilized transport of the coarse fractions in the range $2.1<$ $\tau / \tau_{r i}<2.6$ [Wilcock, 1992]. Both partial transport and fully mobilized transport are evident in the Oak Creek data (Figure 11). The entire range of $\tau_{0}$ represented in this figure falls within a factor of 1.75 , and all fractions appear to be fully mobile at $\tau$ roughly $60 \%$ in excess of the smallest value shown. Such an observation is consistent with the suggestion that many gravel bed rivers adjust to a geometry such that the ratio $\tau_{0} / \tau_{c}$ rarely exceeds values in this range [Parker, 1978]. If this is the case, it is reasonable to suppose that a river is able to move all of the sediment found in its bed within the range of flows that are encountered.

The observation that $\tau_{r i}$ increases with grain size is not dependent on the use of surface-based transport rates; essentially the same $\tau_{r i}$ values would be determined using $q_{b i} / f_{i}$ in Figure 7. The variation of $\tau_{r i}$ with grain size we observe with the BOMC sediment is consistent with our observations for other bimodal sediments. The essential empirical observation is that poorly sorted sediments with two distinct modes in the grain size distribution may have a substantial amount of the finer materials in motion over a range of flows for which the larger sizes are nearly immobile. The occurrence of this range in $\tau_{r i}$ appears to depend on both the separation in size in the modes (a two-part mixture with modes separated by a factor of 3 did not show any size dependence in $\tau_{r i}$ [Wilcock, 1992]) and the proportion in the modes (values of $\tau_{r i}$ for Oak Creek fall within a narrow range of roughly $25 \%$; although the bed sediment has two modes, the finer mode contains only slightly more sediment than the adjoining fractions). Further discussion of the effect of size distribution bimodality on $\tau_{r i}$ is given by Wilcock [1992, 1993].

\section{ConClusions}

We have made observations of fractional transport rates of a sandy gravel sediment in a recirculating flume. The work is novel in two respects. First, the sediment was divided into 14 size fractions, and all of each size fraction was painted a different color. This allows us to determine the bed surface grain size distribution from point counts of photographs. As a result, we have developed, for the first time, a set of coupled observations of flow, fractional transport rates, and bed surface size distribution. The second unusual aspect of the work is that the sediment is much more poorly sorted than most sediments previously investigated in the laboratory, although it is representative of many natural fluvial sandy gravels.

Our observations span a seventeen-fold range of bed shear stress; the total transport rates span more than 5 orders of magnitude. Over this range, we observe that the fractional transport rates can be divided into two parts: one consisting of finer sizes all moving at approximately the same transport rate when scaled by their proportion on the bed surface, and the other consisting of coarser sizes with substantially smaller transport rates. We propose that the decreased mobility of the coarser size fractions occurs because a proportion of the grains in these fractions are rarely, if ever, in motion. As a result, the transport rates of these sizes depend not only on their proportion on the bed surface, but also on the number of surface grains of that fraction that are essentially immobile. The transport rates of the finer, equally mobile, sizes are determined only by their proportion on the bed surface and the total transport rate. The grain size separating these two transport regimes increases consistently with flow strength.

The reference shear stress $\tau_{r i}$ for incipient motion of each size fraction shows a consistent increase with grain size. This result contrasts with that commonly observed for many mixed-size sediments, although it is consistent with our observations of $\tau_{r i}$ in other poorly sorted, strongly bimodal sediments.

Partial transport is evident in our transport data whether scaled by the bed surface or bulk grain size distribution. It is also evident in previously published lab and field data. The distinct threshold we observe between partially and fully 
mobilized transport and the nearly equal mobility of fractions finer than this threshold are clearly evident only when surface-based transport rates are used. Our estimates of $\tau_{r i}$ do not depend on the use of surface-based transport rates; essentially identical $\tau_{r i}$ are calculated when the fractional transport rates are scaled by the bulk mixture size distribution.

Partial transport in our sediment occurs over the range $1<$ $\tau / \tau_{r i}<2.1$. This result is consistent with previous laboratory observations of bimodal sediment transport, although we know of no other surface-based fractional transport data that would permit a direct comparison to be made. It is possible that a state of partial transport exists for any sediment, although the range of shear stress over which partial transport occurs would not necessarily be the same for all sediments.

The bed surface texture changes with bed shear stress in a complex, but systematic fashion. At flows ranging from $1<$ $\tau / \tau_{r}<3$, where $\tau_{r}$ is the shear stress that produces a total transport rate equal to the reference value we use to define incipient motion, the equilibrium bed consistently coarsens with increasing flow strength. We suggest that the mechanisms causing this trend are a gradual filling of bed pore spaces with finer grains and the organization of the finer mobile grains into flow-parallel stripes. At $\tau>3 \tau_{r}$, the bed surface becomes finer with increasing flow strength, which we attribute to a progressive increase in the amount of finer grains released to the closed transport system as more and more coarse clasts are entrained.

These patterns of adjustment among the bed, transport, and flow are particular to a closed, recirculating transport system; different patterns occur in an open system with a fixed sediment input and sediment removal at the downstream end [e.g., Parker et al., 1982a]. Because the equilibrium bed and transport size distributions depend on the laboratory sediment boundary conditions, and because natural transport systems are a complex mix of both idealized laboratory arrangements, consistent comparison of transport observations between the field and either laboratory device must be based on the population of grains immediately available for transport on the bed surface, as done in this paper, rather than on the bulk size distribution of the parent sediment population.

The idea that the transport rates of individual fractions may be controlled not only by their frequency on the bed surface, but also by the proportion of immobile grains within that fraction, provides an additional physical mechanism that contributes to our understanding of fractional transport rates. The definition of bed load transport regions, such as those in Figure 9 and Figure 10, provides a useful conceptual picture of the transport of poorly sorted sediments and a realistic empirical result against which mixed-size sediment transport models may be tested. Because the transport rates are scaled by the proportion of grains immediately available for transport on the bed surface, the correlation between transport rates and bed sediment is direct and unambiguous.

Acknowledgments. This work is supported by grant N00014-91J-1192 from the Office of Naval Research and grant EAR-9004206 from the National Science Foundation. The "bed of many colors" would never have come to light without the help of Amir Erez and Danielle DeClercq. The ideas developed here benefited from discussions with our collaborators on the downstream fining project currently under way at the Saint Anthony Falls Hydraulic Labora- tory at the University of Minnesota: Chris Paola, Gary Parker, Rebecca Seal, and John Southard. The paper was improved by the perceptive comments of Mike Church, Marcelo Garcia, and an anonymous reviewer.

\section{REFERENCES}

Adams, J., Gravel size analysis from photographs, J. Hydraul. Div. Am. Soc. Civ. Eng., 105(HY 10), 1247-1255, 1979.

Church, M. A., D. G. McLean, and J. F. Wolcott, River bed gravels: Sampling and analysis, in Sediment Transport in GravelBed Rivers, edited by C. R. Thome, J. C. Bathurst, and R. D. Hey, pp. 43-88, John Wiley, New York, 1987.

Diplas, P., Bedload transport in gravel-bed streams, J. Hydraul. Eng., 113, 277-292, 1987.

Einstein, H. A., The bedload function for sediment transport in open channel flows, Tech. Bull. 1026, Soil Conserv. Serv., U.S. Dep. of Agric., Washington, D. C., Sept. 1950.

Emmett, W. W., Bedload transport in two large gravel-bed rivers, Idaho and Washington, paper presented at the Third Federal Interagency Sedimentation Conference, Interagency Advis. Comm. on Water Data, Denver, Colo., March 22-25, 1976.

Houjou, K., Y. Shimizu, and C. Ishii, Calculation of boundary shear stress in open channel flow, J. Hydrosci. Hydraul. Eng., 8(2), 21-37, 1990.

Iseya, F., and $\mathbf{H}$. Ikeda, Pulsations in bedload transport rates induced by a longitudinal sediment sorting: $A$ flume study using sand and gravel mixtures, Geogr. Ann., 69(A), 15-27, 1987.

Jackson, W. L., and R. L. Beschta, A model of two-phase transport in an Oregon Coast Range stream, Earth Surf. Processes Landforms, 7, 517-527, 1982.

Kellerhals, R., and D. I. Bray, Sampling procedures for coarse alluvial sediments, J. Hydraul. Div. Am. Soc. Civ. Eng., 97(HY8), 1165-1180, 1971.

Kuhnle, R. A., Fractional transport rates of bedload on Goodwin Creek, in Dynamics of Gravel-Bed Rivers, edited by P. Billi, R. D. Hey, C. R. Thorne, and P. Tacconi, pp. 141-155, John Wiley, New York, 1992.

Leopold, L., Sediment size that determines channel morphology, in Dynamics of Gravel-Bed Rivers, edited by P. Billi, R. D. Hey, C. R. Thorne, and P. Tacconi, pp. 297-307, John Wiley, New York, 1992.

Milhous, R. T., Sediment transport in a gravel-bottomed stream, Ph.D. thesis, Oreg. State Univ., Corvallis, 1973.

Paola, C., G. Parker, R. Seal, S. K. Sinha, J. B. Southard; and P. R. Wilcock, Downstream fining by selective deposition in a laboratory flume, Science, 258, 1757-1760, 1992.

Parker, G., Self-formed straight rivers with equilibrium banks and mobile bed, 2, The gravel river, J. Fluid Mech., 89(1), 127-146, 1978.

Parker, G., Surface-based bedload transport relation for gravel rivers, J. Hydraul. Res., 28, 417-436, 1990.

Parker, G., and P. C. Klingeman, On why gravel bed streams are paved, Water Resour. Res., 18, 1409-1423, 1982.

Parker, G., and A. J. Sutherland, Fluvial armor, J. Hydraul. Res., 28, 529-544, 1990 .

Parker, G., S. Dhamotharan, and S. Stefan, Model experiments on mobile, paved gravel bed streams, Water Resour. Res., 18(5), 1395-1408, $1982 a$.

Parker, G., P. C. Klingeman, and D. L. McLean, Bedload and size distribution in paved gravel-bed streams, J. Hydraul. Div. Am. Soc. Civ. Eng., 108(HY4), 544-571, $1982 b$.

Proffitt, G. T., and A. J. Sutherland, Transport of non-uniform sediments, J. Hydraul. Res., 21(1), 33-43, 1983.

Vanoni, V. A., and N. H. Brooks, Laboratory studies of the roughness and suspended load of alluvial streams, Rep. E68, Sediment. Lab., Calif. Inst. of Technol., Pasadena, 1957.

Whiting, P. J., W. E. Dietrich, L. B. Leopold, T. G. Drake, and R. L. Shreve, Bedload sheets in heterogeneous sediment, Geology, 16, 105-108, 1988.

Wilcock, P. R., Methods for estimating the critical shear stress of individual fractions in mixed-size sediment, Water Resour. Res., 24, 1127-1135, 1988.

Wilcock, P. R., Experimental investigation of the effect of mixture properties on transport dynamics, in Dynamics of Gravel-Bed 
Rivers, edited by P. Billi, R. D. Hey, C. R. Thome, and P. Tacconi, pp. 109-131, John Wiley, New York, 1992.

Wilcock, P. R., Critical shear stress of natural sediments, $J$. Hydraul. Eng., in press, 1993.

Wilcock, P. R., and J. B. Southard, Experimental study of incipient motion in mixed-size sediment, Water Resour. Res., 24, 1137$1151,1988$.

Wilcock, P. R., and J. B. Southard, Bed load transport of mixed-size sediment: Fractional transport rates, bed forms, and the development of a coarse bed-surface layer, Water Resour. Res., 25, 1629-1641, 1989.
Wolman, M. G., A method of sampling coarse river-bed material, Eos Trans. AGU, 35, 951-956, 1954.

B. W. McArdell and P. R. Wilcock, Department of Geography and Environmental Engineering, Johns Hopkins University, Baltimore, MD 21218.

(Received May 11, 1992; revised November 5, 1992; accepted November $19,1992$. ) 